\title{
AMBIENTES DE APRENDIZAJE UNA APROXIMACIÓN CONCEPTUAL
}

\author{
Jakeline Duarte Duarte \\ Docente de la Universidad de Antioquia, Colombia
}

Son varias las disciplinas relacionadas de alguna manera con el concepto de ambientes de aprendizaje, también llamados, ambientes educativos, términos que se utilizan indistintamente para aludir a un mismo objeto de estudio. Desde la perspectiva ambiental de la educación, la ecológica, la psicología, la sistémica en teoría del currículo, así como enfoques propios de la etología y la proxémica, entre otros, se ha contribuido a delimitar este concepto, que actualmente demanda ser reflexionado dada la proliferación de ambientes educativos en la sociedad contemporánea y que no son propiamente escolares.

Conceptualizar los ambientes educativos desde la interdisciplinariedad, enriquece y hace más complejas las interpretaciones que sobre el tema puedan construirse, abre posibilidades cautivantes de estudio, aporta nuevas unidades de análisis para el tratamiento de problemas escolares y sobre todo, ofrece un marco conceptual con el cual comprender mejor el fenómeno educativo, y de ahí poder intervenirlos con mayor pertinencia.

En la contemporaneidad la escuela ha perdido presencia en la formación y socialización de los jóvenes, y cohabita con otras instancias comunitarias y culturales que contribuyen a ello, como los grupos urbanos de pares y los medios de comunicación. En correspondencia con ello, las grandes transformaciones de la educación en los últimos años, suponen el establecimiento de nuevas modalidades y estrategias de formación y socialización, que le confieren a la Pedagogía un claro sentido social que rebasa los escenarios escolares, dirigiéndose a la atención de problemas asociados con la exclusión, los conflictos socio-educativos y el desarrollo humano de los sujetos y las comunidades, en escenarios que no son necesariamente escolares.

La emergencia histórica de "nuevos" escenarios para la Pedagogía, sobrepasando los tradicionales linderos escolares que la monopolizaban, se remontan a los años sesenta en Latinoamérica con las experiencias educativas lideradas por comunidades e instituciones, con ideales liberacionistas en contextos de marginación, explotación económica y dominación política (Giroux, 1997).

Debido a la reconfiguración cultural que ha sufrido la educación en la actualidad, se viene reconociendo una "generalización" de lo educativo en diferentes escenarios y procesos culturales, de modo que pensadores como Regis Debray (1997) señalan que la cultura contiene un "segmento pedagógico". Este señalamiento es bien importante, pues evidencia el declive de la hegemonía de la institución escolar en las sociedades contemporáneas, donde los significados de la Pedagogía se habían restringido a lo escolar, olvidándose sus significados complejos y polisémicos referidos a su sentido social y a prácticas sociales históricas muy diversas que le eran propias. Este fenómeno que toma forma en la actualidad, 
recuerda que antes de existir la forma "escuela", las sociedades aprendían y se socializaban por medio de otras agencias culturales como la familia, las cofradías, los gremios de artesanos donde se transmitía el saber de los oficios a las nuevas generaciones, la comunidad local con sus tradiciones y la parroquial, entre otras.

Igualmente, la educación se halla "descentrada" de sus viejos escenarios como la escuela, y sus prácticas, actores y modalidades han mutado y traspasado sus muros para extender su función formativa y socializadora a otros ambientes como la ciudad y las redes informáticas, a sujetos que no son necesariamente infantes sino también adultos, y mediando otras narrativas y saberes que escapan a la racionalidad ilustrada centrada en el discurso racionalista del maestro y en el libro, vehículo cultural por excelencia desde la llustración.

Como se sugiere hasta acá, el objeto abordado en éste artículo supone un acercamiento conceptual de tipo exploratorio, a lo que se ha denominado ambientes de aprendizaje, también asumidos como ambientes educativos, en tanto hace referencia a lo propio de los procesos educativos que involucran los objetos, tiempos, acciones y vivencias de sus participantes. Para ello se parte de una revisión de bibliografía que no pretende ser exhaustiva y de algunas experiencias institucionales en Colombia, insumos desde donde se inicia una reflexión teórica sobre el tema.

\section{UNA NOCIÓN DIVERSA Y COMPLEJA}

Según Daniel Raichvarg (1994, pp. 21-28), la palabra "ambiente“ data de 1921, y fue introducida por los geógrafos que consideraban que la palabra "medio" era insuficiente para dar cuenta de la acción de los seres humanos sobre su medio. El ambiente se deriva de la interacción del hombre con el entorno natural que lo rodea. Se trata de una concepción activa que involucra al ser humano y por tanto involucra acciones pedagógicas en las que, quienes aprenden, están en condiciones de reflexionar sobre su propia acción y sobre las de otros, en relación con el ambiente.

Desde otros saberes, el ambiente es concebido como el conjunto de factores internos -biológicos y químicos-y externos, -físicos y psicosociales- que favorecen o dificultan la interacción social. El ambiente debe trascender entonces la noción simplista de espacio físico, como contorno natural y abrirse a las diversas relaciones humanas que aportan sentido a su existencia. Desde esta perspectiva se trata de un espacio de construcción significativa de la cultura.

El desarrollo de la noción de ambiente ha derivado a otros ámbitos como los de la cultura y la educación, para definir dinámicas y procesos específicos que otros conceptos o categorías no permiten. Según lo manifiesta Lucié Sauvé (1994, pp. 21-28), el estudio de los diferentes discursos y la observación de las diversas prácticas en la educación relativa al ambiente ha permitido identificar seis concepciones sobre el mismo: 
1. El ambiente como problema... para solucionar: este modelo intenta llevar al estudiante a la identificación de problemas ambientales después de apropiarse unos conocimientos relacionadas con la investigación, evaluación y acción de los asuntos ambientales.

2. El ambiente como recurso...para administrar. Se refiere al patrimonio biológico colectivo, asociado con la calidad de vida. Por ser un recurso, el ambiente se agota y se degrada, por ello se debe aprender a administrarlo con una perspectiva de desarrollo sostenible y de participación equitativa.

3. El ambiente como naturaleza....para apreciar, respetar y preservar. Ello supone el desarrollar de una alta sensibilidad hacia la naturaleza y su conocimiento y la toma de conciencia de que somos parte de ella.

4. El ambiente como biosfera... para vivir juntos por mucho tiempo. Lo cual invita a reflexionar en una educación global, que implica la comprensión de los distintos sistemas interrelacionados: físicos, biológicos, económicos, políticos. Desde ésta noción se otorga un especial interés a las distintas culturas y civilizaciones y se enfatiza el desarrollo de una comunidad global (ciudadanía global), con una responsabilidad global.

5. El ambiente como medio de vida...para conocer y para administrar. Es el ambiente cotidiano en cada uno de los espacios del hombre: Escolar, familiar, laboral, ocio. El ambiente propio para desarrollar un sentimiento de pertenencia, donde los sujetos sean creadores y actores de su propio medio de vida.

6. El ambiente comunitario...para participar. Se refiere a un medio de vida compartido, solidario y democrático. Se espera que los estudiantes se involucren en un proyecto comunitario y lo desarrollen mediante una acción conjunta y de reflexión crítica.

Cada una de estas concepciones define unas prácticas que desde su especificidad se complementan, de manera que pensar en el ambiente implica una realidad compleja y contextual, que sólo se puede abordar desde la pluralidad de perspectivas para pensar el ambiente educativo.

\section{UNA LECTURA SOBRE LO PREVIO}

La Secretaría de Educación y Cultura de Antioquia, en Colombia, viene realizando acciones orientadas al desarrollo de las prácticas investigativas por parte de los docentes. Actualmente existen grupos de maestros realizando investigaciones sobre ambientes de aprendizaje en relación con los procesos cognitivos, las relaciones participativas y democráticas de la comunidad educativa y los ambientes lúdicos. Allí, el elemento tecnológico no aparece con la fuerza con que debería presentarse, si se atiende a los cambios contemporáneos al respecto. A manera de antecedentes, es importante mencionar algunos estudios y experiencias que se han desarrollado en el ámbito latinoamericano, de forma que permita tener una idea sobre la manera como se ha ido configurando el objeto central de este artículo.

El estudio de Hernando Romero (1997), presenta un análisis del espacio educativo como parte de la naturaleza de las actividades académicas, administrativas y de proyección social. Expone los campos de desarrollo y cómo se articula en ellos el espacio educativo, la relación existente entre este y la calidad de la educación, y finalmente analiza las relaciones de poder que propician los espacios educativos. Según el 
autor, no todos los espacios físicos son válidos para todos los modelos educativos en la perspectiva de lograr la excelencia académica, por eso el espacio forma parte inherente de la calidad de la educación: Los espacios consagran relaciones de poder, tanto en el proceso pedagógico como en el organizacional y de poder gobernativo.

La relación entre la lúdica y el aprendizaje, es el tema abordado por uno de los estudios de la Fundación FES (1993, pp. 14-20), en donde se presenta una mirada a las complejas relaciones que existentes entre el juego y la pedagogía. Se sugiere asumir el juego y utilizar los materiales educativos desde una postura crítica e innovadora que permita contribuir a la construcción del conocimiento con los niños que asisten a las escuelas colombianas. Se destaca que entre muchos pedagogos ha existido la concepción del juego como mediador de procesos, que permite incentivar saberes, generar conocimientos y crear ambientes de aprendizaje, mientras que otros han optado por una oposición entre juego y aprendizaje.

En una experiencia educativa realizada por Erick de Corte (1995, pp. 5-19) en Uruguay, se analizan los diferentes aportes de las ciencias de la mente al mejoramiento de la práctica educativa. El trabajo tuvo como guía tres preguntas claves: Primero, ¿qué tipos de conocimientos, estrategias cognitivas y cualidades afectivas deben ser aprendidos, de manera que los alumnos tengan disposición para aprender a pensar y resolver problemas con habilidad? Segundo, ¿qué tipo de procesos de aprendizaje deben ser llevados a cabo por los alumnos para lograr la pretendida disposición, incluyendo la mejora de categorías de conocimientos y habilidades? Y, tercero, ¿cómo pueden crearse ambientes de aprendizaje lo suficientemente dinámicos y poderosos para lograr en los alumnos una disposición a aprender a pensar activamente?

El estudio detecta cuatro componentes de aprender, pensar y resolver problemas con habilidad: un cuerpo teórico organizado y flexible, métodos heurísticos, habilidades metacognitivas, aspectos afectivos, actitudes, motivos y emociones. Cobra especial importancia la metacognición, ya que su desarrollo favorece la transferencia de habilidades adquiridas en un dominio del conocimiento hacia otros. Estos pilares para el aprendizaje autónomo remiten el análisis de la naturaleza del aprendizaje. Así, enuncia algunas de sus características: proceso constructivo, acumulativo, autorregulado, intencional; se produce en un contexto particular, es interactivo y cooperativo. A partir de las dos categorías analizadas se destaca un análisis acerca de los ambientes de aprendizajes poderosos y dinámicos. En la búsqueda de nuevas claves que posibiliten la creación de ambientes de aprendizajes estimulantes y eficientes, el autor se detiene en experiencias exitosas y en los modelos teóricos que los sustentan. De este modo, presenta el modelo de contrato de aprendizaje cognitivo propuesto por Collins, Brown y Newman. A partir de esta teoría Brown y Campione han desarrollado un proyecto de desarrollo de comunidades de aprendizaje.

A manera de conclusión, en el estudio se dice que un individuo aprende a través de un proceso activo, cooperativo, progresivo y autodirigido, que apunta a encontrar significados y construir conocimientos que surgen, en la medida de lo posible, de las experiencias de los alumnos en auténticas y reales situaciones. 
La posición del alumno cambia, puesto que progresivamente debe asumir la responsabilidad de sus propios procesos de aprendizaje. Cambia la posición del docente, quien deja ser la única fuente de información y se convierte en un activo participante de la comunidad de aprendizaje, pues define un clima estimulante en el plano intelectual, que funciona como modelo para la definición y solución de problemas, realiza preguntas desafiantes, propicia el feedback y la ayuda necesaria a sus alumnos y favorece en ellos la autoconducción de sus aprendizajes. Mucho más que un cambio de técnicas, esta nueva visión exige un cambio de mentalidad en todos los involucrados en la enseñanza, especialmente directores y docentes.

Frente a los graves problemas de violencia y conflicto social que afectan a la sociedad colombiana, el departamento de Antioquia viene desarrollando una propuesta educativa llamada: La escuela como cátedra viva de convivencia y paz. Se trata de una propuesta que hace de la convivencia democrática un modo de ser y de actuar en la escuela. Promueve la construcción participativa y solidaria de alternativas pedagógicas, curriculares, administrativas, culturales y sociales que propicien mejores ambientes de convivencia institucional y social; y se desarrollan estrategias metodológicas y formas de concertación que favorecen la formación integral y promueven la socialización en la escuela (SEDUCA, 2000).

La unidad de análisis de éste programa corresponde a la convivencia escolar, entendida como la interacción de las relaciones pedagógicas, personales, de gestión, de gobierno escolar y las relaciones escuela-comunidad. Se trata de la búsqueda de la convivencia escolar, concebida como proyecto de transformación de la cultura escolar, para que en ella y desde ella, cada uno de sus protagonistas sea respetado y reconocido como actor fundamental y en el encuentro diario se construya y recree la paz. Esta búsqueda incluye el aula de clase y los ámbitos más amplios de la comunidad local y regional.

Una vez realizado un breve recorrido por algunas experiencias sobre ambientes de aprendizaje, se hace necesario iniciar una conceptualización teórica, que delimite mas claramente el objeto del presente escrito.

\section{¿QUÉ SE ENTIENDE POR AMBIENTE EDUCATIVO?}

El ambiente es concebido como construcción diaria, reflexión cotidiana, singularidad permanente que asegure la diversidad y con ella la riqueza de la vida en relación (OSPINA, 1999). La expresión ambiente educativo induce a pensar el ambiente como sujeto que actúa con el ser humano y lo transforma. De allí se deriva que educa la ciudad (la ciudad educadora) (Naranjo y Torres, 1996), la calle, la escuela, la familia, el barrio y los grupos de pares, entre otros. Reflexionar sobre ambientes educativos para el sano desarrollo de los sujetos convoca a concebir un gran tejido construido, con el fin específico de aprender y educarse.

Otra de las nociones de ambiente educativo remite al escenario donde existen y se desarrollan condiciones favorables de aprendizaje. Un espacio y un tiempo en movimiento, donde los participantes desarrollan capacidades, competencias, habilidades y valores (Centro de Educación en Apoyo a la Producción y al Medio Ambiente. A. C. CEP Parras, México). Para los realizadores de experiencias 
comunitarias dirigidas a generar ambientes educativos, se plantean dos componentes en todo ambiente educativo: los desafíos y las identidades. Los desafíos, entendidos como los retos y las provocaciones que se generan desde las iniciativas propias o las incorporadas por promotores, educadores y facilitadores, entre otros. Son desafíos en tanto son significativos para el grupo o la persona que los enfrenta, y con la menor intervención de agentes externos. Los desafíos educativos fortalecen un proceso de autonomía en el grupo y propician el desarrollo de los valores.

Los ambientes educativos también están signados por la identidad, pues la gestión de las identidades y lo cultural propio es la posibilidad de creación de relaciones de solidaridad, comprensión y apoyo mutuo e interacción social.

El ambiente educativo no se limita a las condiciones materiales necesarias para la implementación del currículo, cualquiera que sea su concepción, o a las relaciones interpersonales básicas entre maestros y alumnos. Por el contrario, se instaura en las dinámicas que constituyen los procesos educativos y que involucran acciones, experiencias vivencias por cada uno de los participantes; actitudes, condiciones materiales y socioafectivas, múltiples relaciones con el entorno y la infraestructura necesaria para la concreción de los propósitos culturales que se hacen explícitos en toda propuesta educativa.

Teniendo en cuenta estos aspectos la pregunta por los ambientes educativos ya no resulta tan obvia y de sencilla respuesta. Actualmente, por ambiente educativo se refiere una u otra denominación, no sólo se considera el medio físico sino las interacciones que se producen en dicho medio. Son tenidas en cuenta, por tanto la organización y disposición espacial, las relaciones establecidas entre los elementos de su estructura, pero también, las pautas de comportamiento que en él se desarrollan, el tipo de relaciones que mantienen las personas con los objetos, las interacciones que se producen entre las personas, los roles que se establecen, los criterios que prevalecen y las actividades que se realizan.

A continuación se mencionan algunas necesidades, identificadas como la columna vertebral de la educación, y que aportan algunas pistas para pensar en los ambientes educativos, ellas son:

- Planteamiento de problemas, diseño y ejecución de soluciones.

- Capacidad analítica investigativa

- Trabajo en equipo, toma de decisiones y planeación del trabajo.

- Habilidades y destrezas de lectura comprensiva y de expresión oral y escrita.

- Capacidad de razonamiento lógico-matemático.

- Capacidad de análisis del contexto social y político nacional e internacional.

- Manejo de la tecnología informática y del lenguaje digital.

- Conocimiento de idiomas extranjeros.

- Capacidad de resolver situaciones problemáticas.

A la hora de hablar de ambientes educativos y reconociendo que no obstante que han tenido lugar transformaciones estructurales en la cultura contemporánea que le han sustraído a la escuela el monopolio 
que ejercía de lo educativo, la escuela todavía tiene una gran importancia y un gran peso social y cultural, y por ello merece caracterizarse y fundamentarse el problema de los ambientes desde ella.

\section{LA ESCUELA Y EL MEDIO}

La escuela es concebida de diversas maneras y cada una define estilos diferentes de interacción. Juan Carlos Pérgolis (2000, pp. 33-34) la concibe como un mediador fundamental de la cultura urbana, en tanto puede expresarse en tres dimensiones:

- La escuela como lugar de la ciudad: ¿es parte del barrio, es del barrio, está en el barrio? La escuela explica y propone sus fronteras y su localización. Por lo general ha estado asociada a una idea de lugar con fronteras duras y lejanas de la ciudad, como aislada en un gran territorio.

- La escuela como formación para la ciudad: La escuela parece como lugar de significado. Independiente del territorio y la localización, la escuela se asume como lugar para el todo de la ciudad y ve a ésta como su proyecto. Es una ciudad en pequeño.

- La escuela como punto de encuentro: aquí la escuela opera para ser un foro en el que las diferentes versiones de ciudad se encuentren. Todos los sectores de la ciudad se reúnen y ponen en común sus propias comprensiones. Así, la escuela se ofrece como lugar de transacción hacia la construcción de una ciudad compartida.

Según Pérgolis, estas tres dimensiones pueden operar individualmente o cruzarse en diversas combinaciones. De esta manera los ambientes educativos pueden ser vistos como contenido, como proyecto o como construcción y fundamentalmente deben responder a una escuela donde predomina la complejidad; en donde cada institución educativa es reconocida desde sus particularidades. Sin embargo, estas complejas consideraciones declinan frente al carácter disciplinario y de control social que ha moldeado a la escuela y que todavía conserva. Según Gildardo Moreno y Adela Molina (1993), en las escuelas actuales el ambiente educativo se mantiene inalterado: En cuanto al ordenamiento sigue siendo prescriptivo, en cuanto a las relaciones interpersonales es dominado por consideraciones asimétricas de autoridad (autoritarismo) En cuanto a la relación con el conocimiento está inmerso en concepciones transmisionistas y en lo referente a valores se halla sumido en una farsa en donde lo que se hace está orientado más por la conveniencia que por consideraciones éticas, en donde se privilegia "el saber racionalista e instrumental" y se descuida el arte y las diversas posibilidades de reconocimiento cultural y de otros saberes.

Parece que en la sociedad occidental, afirman los autores, existe una actitud hacia la aceptación pasiva de los ordenamientos sociales y no hacia la transformación o a los cuestionamientos que conduzcan a convivencias sociales diferentes. Tradicionalmente la escuela ha sido leída como una organización cerrada y que en sí misma pareciera un conjunto de mundos individuales aislados entre sí. Se trata de un aislamiento que sobrepasa las dimensiones físicas, las aulas, y llega hasta el aislamiento psico-sociológico en el que parecen convivir distintos sujetos. Los autores señalan como características de estos ambientes de aprendizaje: 
1. El trabajo del estudiante y la actividad profesional del maestro carecen de sentido y de posibilidad de autorrealización.

2. Como el conocimiento se considera posible sin la existencia de tensiones afectivas, del deseo del saber y de la voluntad del saber, el resultado es un conocimiento sin comprensión.

3. Las actividades y la organización escolar se fundan en normas que son ajenas a un proyecto ético, propio de estudiantes y maestros.

Redimensionar los ambientes educativos en la escuela implica, además de modificar el medio físico, los recursos y materiales con los que se trabaja, exige un replanteamiento de los proyectos educativos que en ella se desarrollan y particularmente los modos de interacciones de sus protagonistas, de manera que la escuela sea un verdadero sistema abierto, flexible, dinámico y que facilite la articulación de los integrantes de la comunidad educativa: maestros, estudiantes, padres, directivos y comunidad en general. En éste orden de ideas, la escuela "permeable" se caracteriza porque se concibe abierta, lo mas arraigada posible a su medio, con fronteras no claramente delimitables y relaciones con el conocimiento y entre los individuos que buscan establecer vivencias culturales cruzadas por prácticas democráticas altamente participativas.

Es posible pensar la escuela en coherencia con una concepción de educación como un sistema abierto, en la medida en que se supone que su estructura y funcionamiento se realiza en un intercambio permanente con su contexto. Las interacciones permanentes y sustanciales implican que el afuera no sea algo ajeno o desconectado de ella y de los procesos que le son propios. Desde esta perspectiva hablar de ambiente educativo escolar es concebir no una sumatoria de partes llamadas sectores, escenarios, actores, sino propender su funcionamiento sistémico, integrado y abierto.

De nada serviría si un espacio se modifica introduciendo innovaciones en sus materiales, si se mantienen inalterables unas acciones y prácticas educativas cerradas, verticales, meramente instruccionales. Por ello el papel real transformador del aula está en manos del maestro, de la toma de decisiones y de la apertura y coherencia entre su discurso democrático y sus actuaciones, y de la problematización y reflexión crítica que él realice de su práctica y de su lugar frente a los otros, en tanto representante de la cultura y de la norma.

Se trata de propiciar un ambiente que posibilite la comunicación y el encuentro con las personas, dar a lugar a materiales y actividades que estimulen la curiosidad, la capacidad creadora y el diálogo, y donde se permita la expresión libre de las ideas, intereses, necesidades y estados de ánimo de todos y sin excepción, en una relación ecológica con la cultura y la sociedad en general.

La escuela es después de la familia y aún de otros espacios de formación de actitudes y valores, el espacio determinante en la formación individual. Es por ello por lo que puede ser definitivo pensar una escuela del sujeto cuyos ambientes educativos apunten a la formación humana y contemporánea de individuos, alumnos y maestros conscientes de su lugar en la sociedad. Pensar en una escuela cuyos ambientes educativos tomen en consideración las interacciones entre sujetos vistos como totalidades, esto es que vaya más allá de lo cognoscitivo y que se consideren los sentimientos y deseos en relación con el 
saber, que vaya más allá de las respuestas correctas y tome en cuenta los errores, que en vez de propiciar la farsa y la obediencia propicie la sinceridad y la rectitud y los deseos de los sujetos.

Como espacio para la vivencia de la democracia, la escuela no se limita a ser un escenario para el diálogo de saberes, es también un espacio para el intercambio de intereses, para la definición de intencionalidades comunes y para el establecimiento de criterios de acción que tengan por objeto la consolidación de proyectos culturales y sociales, basado sobre el reconocimiento mutuo en igualdad de oportunidades, en contraste con la búsqueda violenta de la homogeneidad y el igualitarismo (Moreno y Molina, 1993).

Cada uno de los participantes de la actividad escolar tiene unos referentes diferentes al hablar de la escuela, generalmente los especialistas y los profesores siempre hablan de planes de estudio y régimen disciplinario, mientras que los padres de familia hablan de formas de relación, tolerancia, comprensión y los alumnos hablan de las relaciones afectivas. Los maestros con menos frecuencia de ambiente educativo, de la red viviente que agencia ideas y afectos, en un marco de acción vital que de lugar a la pasión por el saber.

De acuerdo con lo expuesto se reconocen diversos espacios del sujeto, que se convierten en ambientes educativos, pero a la vez no se puede desconocer que uno de ellos tiene una trascendencia en la formación y estructuración de la cultura y es la escuela.

\section{EL AULA COMO LUGAR DE ENCUENTRO}

Dentro del mundo de la escuela, tal vez es el aula de clases donde se ponen en escena las más fieles y verdaderas interacciones entre los protagonistas de la educación intencional, maestros y estudiantes. Una vez cerradas las puertas del aula se da comienzo a interacciones de las que sólo pueden dar cuenta sus actores. Es aquí donde el maestro se hace y se muestra, aquí ya los deseos se convierten en una realidad, ya no es el mundo de lo que podría ser, sino el espacio de lo que es.

Son muchos los investigadores que se han dedicado a estudiar la clase como el momento crucial del acto educativo. En la investigación realizada por María Isabel Cano (1995) en cuanto al espacio físico y sus determinantes en las interacciones sociales en la escuela, se plantean unos principios como hipótesis de trabajo, que merecen ser retomados acá.

Principio № 1: El ambiente de la clase ha de posibilitar el conocimiento de todas las personas del grupo y el acercamiento de unos hacia otros. Progresivamente ha de hacer factible la construcción de un grupo humano cohesionado con los objetivos, metas e ilusiones comunes.

De este principio surge la pregunta por lo social, la posibilidad de construirse a partir del otro. Es el paso de la socialización a partir de la misma individuación, espacio para acceder a un grupo cohesionado, uno de los mayores aprendizajes de tipo socio-afectivo y cognitivo que pueda tener un ser humano. Gracias a la interacción con otros, el niño empieza a reconocer que además de sus propias necesidades, gustos, 
intereses e ideas, existen las de muchos otros que conviven con él. Por tanto en el aula de clase se debe favorecer el desarrollo de la autonomía de los sujetos en el marco de unas relaciones cooperativas con los demás y con el medio. El desarrollo integral del niño debe estar unido y a la vez posibilitado por la construcción de un grupo cohesionado y solidario. María Isabel Cano y Ángel Lledó (1995) han hecho un valioso análisis de la relación entre la organización y disposición espacial y los fenómenos sociales que se dan el grupo-clase y sus actividades. Parece observarse una enorme coincidencia entre la estructura de las relaciones y la disposición espacial, elemento de gran importancia para propiciar ambientes de aprendizaje que permitan la individuación pero también la socialización. Los siguientes diagramas permiten apreciar lo expuesto. 

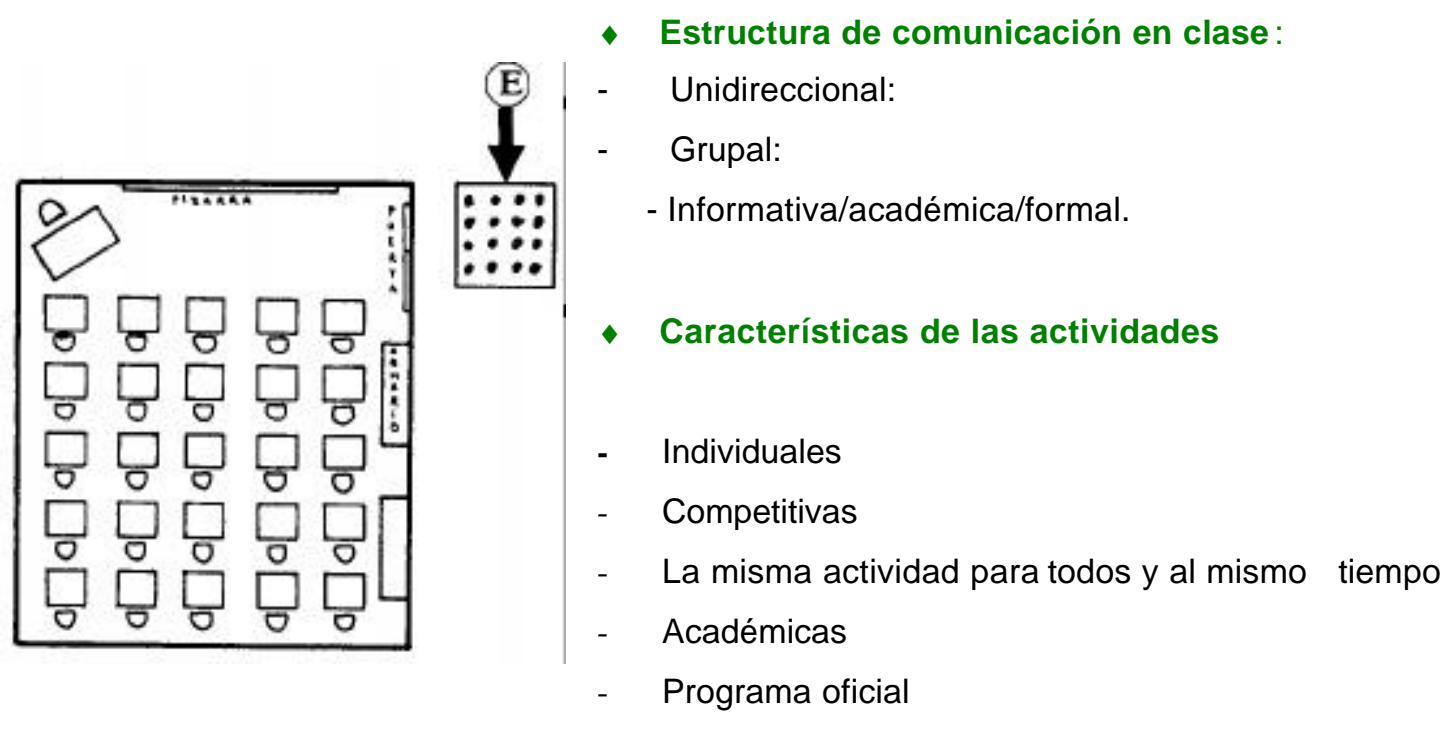

B) EJEMPLO DE TIPO DE ORGANIZACIÓN ESPACIAL “ACTIVA":

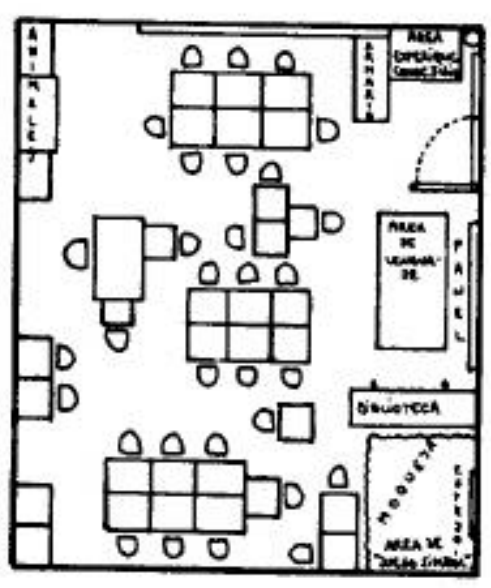

- Estructura de comunicación en clase:

Bidireccional:

todos son Emisores y Receptores

Grupal e Individual

Integradora de contenidos "formales" e

"informales": metodológica, efectiva...

Características de las actividades:

-Opcionalidad del alumno.

Grupales e individuales.

ooperativas.

Posibilidad de actividades distintas y simultáneas 
Principio № 2: "El entorno escolar ha de facilitar a todos y a todas el contacto con materiales y actividades diversas que permitan abarcar un amplio abanico de aprendizajes cognitivos, afectivos y sociales"

Es conocido por los profesionales en pedagogía, que el aprendizaje en los niños se propicia mediante la interacción del niño con el medio físico y social, mediado por el lenguaje. Reconocer cómo aprenden los niños tiene repercusiones en lo que se refiere a la construcción del ambiente del aula, pensado como ambiente dinámico, con la posibilidad de recrearse, cambiarse y suprimirse, dependiendo de los proyectos que se estén desarrollando.

Principio № 3: "El medio ambiente escolar ha de ser diverso, debiendo trascender la idea de que todo aprendizaje se desarrolla entre las cuarto paredes del aula. Deberán ofrecerse escenarios distintos, -ya sean construidos o naturales- dependiendo de las tareas emprendidas y de los objetivos perseguidos".

En la intención de involucrar espacios exteriores como prolongación de la actividad escolar, y lo escolar mismo como un cuerpo poroso que no da la espalda a su contexto, existen varias propuestas. Casi todas hacia el desarrollo de currículos integradores de distintos escenarios y que consideran como un todo el conjunto espacial entre el interior y exterior del entorno físico del aula.

Principio № 4: "El entorno escolar ha de ofrecer distintos subescenarios de tal forma que las personas del grupo puedan sentirse acogidas según distintos estados de ánimo, expectativas e intereses".

Parece existir, según lo establecen los autores citados, una relevancia entre los estados de ánimo, las relaciones personales y los objetivos de la actividad, tanto como las características del material y las metodologías que se emplean. Por consiguiente es importante crear ambientes en el aula, cualitativamente diferentes: unos orientados hacia la lúdica, la relajación, la libertad de hacer, otros espacios más individuales y otros más colectivos.

Principio № 5: "El entorno ha de ser construido activamente por todos los miembros del grupo al que acoge, viéndose en él reflejadas sus peculiaridades, su propia identidad".

Así como ocurre en otros ambientes sociales, la casa, y en ella el cuarto, los individuos tienen el derecho a decidir sobre la organización de su espacio, en el aula con mayor razón se debe permitir que sus habitantes participen en su estructuración, pues son ellos quienes vivirán en ella la mayor parte de su tiempo, por no decir de sus vidas. Esto genera en los estudiantes sentido de identidad y marca la territorialidad que todo ser humano requiere para desplegar su vida.

En síntesis, se pretende propiciar ambientes altamente favorables para la convivencia social y los aprendizajes, por lo tanto se propone:

- Establecer una interacción comunicativa efectiva y circular entre el maestro, el estudiante y el grupo.

- Considerar las diferencias individuales. 
- Fortalecer el autoconcepto y autoestima en los estudiantes y el maestro.

- El manejo de la clase debe basarse en sólidas relaciones de grupo.

\section{AMBIENTE EDUCATIVO Y ESTÉTICA SOCIAL}

El carácter ético del entorno escolar es un elemento fundamental en los procesos de aprendizaje. La racionalidad sensorial y la tematización de la afectividad, deben dar lugar al despliegue de las subjetividades en sus configuraciones estéticas. Desde la perspectiva de Luis Carlos Restrepo (1993), se puede entender el ambiente educativo como un clima cultural, campo de agenciamientos simbólicos que inscriben al sujeto en ese medio de cultivo específicamente humano, el lenguaje.

En la escuela se generan procesos de construcción y reconstrucción de la identidad subjetiva, dentro de una empresa cuyo propósito es eminentemente ético: "lo que (para Restrepo) determina nuestra actitud ética es a la larga nuestra afectación sensible, la disposición corporal a convivir en ese engranaje de implícitos y no dichos que caracterizan el espacio humano. Afecciones y no argumentos, hábitos y no juicios, gestos más que palabras y proposiciones, es lo que nos queda después de muchos años de trajinar por las aulas y la academia, como sedimento residual de experiencias y aprendizajes". Estos perceptos y disposiciones sensibles, según Restrepo, son construidos de manera sutil en la interacción cotidiana, en la dinámica del aula, en los intercambios afectivos y los ejercicios del poder que cruzan tanto la familia como la escuela.

Todo problema ético remite a un asunto estético, al campo de lo que se podría llamar "estética social" (Restrepo, sf.) en tanto está en juego una forma de sensibilidad y es social porque no se trata de la experiencia individual, sino de la afección que se comparte con el grupo y que decide el curso del comportamiento del sujeto y su escena en público. En esta perspectiva, la noción propuesta por André Leroi-Gourhan (1971, p. 267) se compadece con lo expuesto hasta ahora. Para este peleontólogo francés, la estética social o "comportamiento estético" remite no a las nociones de la filosofía sobre lo bello en la naturaleza y en el arte. No se trata tampoco de la sensibilidad eminentemente auditiva o visual para el arte “...sino de rebuscar, en toda la densidad de las percepciones, cómo se constituye, en el tiempo y en el espacio, un código de las emociones, asegurando al sujeto étnico lo más claro de la inserción afectiva en su sociedad".

Preguntarse por la estética social es hacerlo por la sensibilidad que se forma en la escuela. Negar la afectividad que atraviesa todo proceso de aprendizaje, es desconocer la importancia de ligarse por el deseo a los contextos escolares y sus actores singulares. Es negar las cogniciones afectivas en la construcción del conocimiento. En éste sentido, el trabajo del maestro es posibilitar la formación de sensibilidades, las que se construyen y cultivan en ambientes interhumanos a través de mediaciones e interacciones culturales específicas. De igual manera negar la afectiva es negar también la posibilidad del disfrute y el goce, por ello parte de lo que vive el ser humano también tiene que ver con lo lúdico y placentero, sin deponer la exigencia y esfuerzo que supone todo proceso educativo. En este sentido resulta pertinente dar una mirada a esta dimensión que resalta una de las expresiones más típicamente humanas: lo lúdico. 


\section{AMBIENTES DE APRENDIZAJE LÚDICOS}

La lúdica es una dimensión que cada día ha venido tomando mayor importancia en los ambientes educativos, particularmente porque parece escapar a la pretensión instrumentalista que caracteriza a la escuela. La lúdica se presta a la satisfacción placentera del niño por hallar solución a las barreras exploratorias que le presenta el mundo, permitiéndole su autocreación como sujeto de la cultura, de acuerdo con lo que señala al respecto Huizinga (1987): "La cultura humana ha surgido de la capacidad del hombre para jugar, para adoptar una actitud lúdica".

Aquí es importante resaltar la relación existente entre juego, pensamiento y el lenguaje, tomando el juego como parte vital del niño que le permite conocer su entorno y desarrollar procesos mentales superiores que lo inscriben en un mundo humanizado.

Para el tema que se expone, se trata de incorporar la lúdica en los ambientes educativos, pues da lugar a los procesos de construcción de identidad y pertenencia cognitiva, opción que se sustenta desde el reconocimiento de que lo lúdico también reside en el lenguaje y atraviesa los procesos educativos constituyéndose en medio y fuente que permita relacionar pensamientos para producir pensamientos nuevos. Se debe ser consciente que en la formación del niño y el joven interactúan varios factores, y que lo lúdico es un escenario enriquecedor por lo cual no hay que perderlo de vista, si se quiere abordar unas pedagogías propias del imaginario y representaciones de ellos.

Uno de los elementos que han permitido generar ambientes de aprendizaje lúdicos es la incorporación del juego: Este es un recurso educativo que se ha aprovechado muy bien en los niveles de preescolar y primaria, pero que, a medida que se avanza en la escolaridad tiende a relegarse, a favor de formas más expositivas de enseñanza.

El juego es una función vital sobre la que no es posible aún dar una definición exacta en términos lógicos, biológicos o estéticos. Descrito por sus características, el juego no es "vida corriente" ni "vida real", sino que hace posible una evasión de la realidad a una esfera temporal, donde se llevan a cabo actividades con orientación propia. El aislamiento espacio-temporal en el que tiene lugar el juego genera mundos temporales dentro del mundo habitual, a partir de una actividad particular. El juego introduce en la confusión de la vida y en la imperfección del mundo una perfección temporal y limitada: permite al sujeto crear un orden.

La noción de juego en su forma coloquial, tal como es presentada por algunos autores, se concibe como una actividad u ocupación voluntaria, ejercida dentro de ciertos y determinados límites de tiempo y espacio, que sigue reglas libremente aceptadas, pero absolutamente obligatorias; que tiene un final y que va acompañado de un sentimiento de tensión y de alegría, así como de una conciencia sobre su diferencia con la vida cotidiana. 
Estudiosos del juego (Ferrari, 1994, pp. 47-49) destacan que puede empleársele con una variedad de propósitos dentro del contexto de aprendizaje. Señalan que dos de sus potencialidades básicas, las más importantes, son la posibilidad de construir autoconfianza e incrementar la motivación en el jugador. Es un método eficaz que posibilita una práctica significativa de aquello que se aprende; el juego en la educación ha servido como motivador y a veces como recurso didáctico, sin embargo, en la práctica pedagógica no se ha explorado suficientemente su potencial como espacio de conocimiento y de creatividad.

De este modo, cabe pensar que los ambientes lúdicos pueden ser no sólo ocasión de entretenerse y divertirse, que es lo primero que se asocia con el juego; la sorpresa, lo gracioso, son componentes naturales en el juego. Pero el juego-juego va más allá, permite vivir en micromundos usualmente entretenidos y amigables (al menos no amenazantes), sea situaciones de menor complejidad que las reales, o mucho más allá de estas, fantasiosas y especulativas, pero en cualquier caso ceñidas a las reglas vigentes y en pos de metas valederas. $Y$ es por esto que el juego permite desarrollar la creatividad, pues las reglas, dando un orden a la interacción entre los participantes, no son necesariamente lógicas o ceñidas al comportamiento del mundo físico, cabe inventárselas o concertar unas nuevas de camino; esto brinda una muy sólida base para potenciar las capacidades humanas, para traspasar el umbral de lo conocido, para desarrollar el potencial creativo del ser humano y dar lugar a lo que más caracteriza al hombre: su capacidad para simbolizar el mundo: la "libertad simbólica". Éste aspecto es sumamente destacado y valorado en los estudios de la semiótica y las ciencias sociales contemporáneas. Para el antropólogo Gilbert Durand, el símbolo remite la libertad del sujeto para crearse y crear el mundo: "Así se revela el papel profundo del símbolo: es 'confirmación' de un sentido a una libertad personal. Por eso el símbolo no puede explicitarse (...) Y la potencia poética del símbolo define la libertad humana mejor que ninguna especulación filosófica: esta última se obstina en considerar la libertad como una elección objetiva, mientras que en la experiencia del símbolo comprobamos que la libertad es creadora de un sentido: es poética de una trascendencia en el interior del sujeto más objetivo, más comprometido con el acontecimiento concreto. Es el motor de la simbólica. Es el Ala del Ángel”.

\section{LOS AMBIENTES VIRTUALES. UN DESAFÍO PARA LA EDUCACIÓN.}

El paso del siglo XX al XXI será conocido como el que marcará la transformación de una sociedad basada en las relaciones materiales, a otra que se apoya en las relaciones virtuales comunicativas en su sentido más amplio. Ahora, la existencia humana se desarrolla en la esfera de lo virtual y lo semiológico, constituyendo la comunicación mediática.

En la época actual las relaciones físicas personales empiezan a perder peso, obviamente sin desaparecer, y empieza a tomar fuerza el universo mediático-relacional, el espacio de los lenguajes y el tiempo de las nuevas comunicaciones. Aparece el concepto de cibercultura, como un escenario tecnológico para la producción cultural, de la mediatización de lo social. ${ }^{1}$ Con éste fenómeno, las instituciones, los roles

\footnotetext{
${ }^{1}$ Para Jesús Martín Barbero: "El lugar de la cultura en la sociedad cambia cuando la mediación tecnológica de la comunicación deja de ser meramente instrumental para espesarse, densificarse y convertirse en estructural. Pues la tecnología remite hoy no a la novedad de unos aparatos sino a nuevos modos de
} 
personales, los individuos, las identidades y los grupos se transforman, lo que de alguna manera introduce incertidumbre, desconcierto y a veces desorientación, pero también nuevas posibilidades de organización social e institucional.

Una sociedad de la información, exige una nueva alfabetización basada en los nuevos medios técnicos y en los nuevos lenguajes que ellos suponen. Son muchas las novedades y escasa la toma de conciencia sobre los cambios que se nos presentan. Los sistemas de educación, no son ajenos a este escasísimo discernimiento. Los procesos de enseñanza se ven obligados a indagar como se suscitan en una relación de aprendizaje ya no sólo mediada por el lenguaje oral y escritural sino por el icónico-gráfico, la imagen digital y los variados sistemas de representación que traen consigo nuevas maneras de pensamiento visual.

Es en la mediación como se va pasando de un estado de información al conocimiento, pues la diferencia entre información y conocimiento es que este último está dotado de significación, por ello, las organizaciones que pretenden desarrollar acciones educativas con sus integrantes más allá de pensar en una serie de contenidos, algunas veces llamadas asignaturas e impartidas bajo modelos instruccionales, deben pensar en los fundamentos y directrices didácticas y pedagógicas que la educación digitalizada exige. A partir de la aparición de los medios, el papel del aprendiz, o también llamado alumno se resignifica. Las relaciones con sus profesores, tutores o instructores se modifica así como su relación con el saber mismo. En la medida en que aparecen una amplia gama de fuentes y se consigue un fácil acceso a la información, se desplaza la noción de saber a la de saberes, la noción de verdad a la de verdades, distanciándose la concepción del saber monolítico o el saber constituido, y surgiendo una visión más cercana al "conocimiento como construcción".

Pero las nuevas mediaciones tecnológicas no sólo traen aparejados una transformación estructural en el conocimiento, sino también en los vínculos intersubjetivos que se suceden en la escuela y en las familias. En esta dirección, debe destacarse el papel que cumple y ha cumplido la televisión y la internet con respecto a la familia y a la escuela, pues trae por consecuencia un "desorden cultural" que descompone las formas de autoridad vertical entre los jóvenes, sus padres y maestros. Como lo ha sugerido Jesús MartínBarbero, la televisión "deslegitima" y "deslocaliza" las formas continuas del saber promovido en la escuela desde el texto escrito, que constituye el centro de un modelo lineal mecánico, basado en aprendizajes graduales de acuerdo con las edades evolutivas del niño. Por medio de la televisión el joven accede rápida y cómodamente a un "s aber visual" que subvierte el modelo escolar por etapas, legitimado por la autoridad del maestro. Trasladada al hogar, la televisión cortocircuita las relaciones de autoridad entre padres e hijos, al permitir que estos últimos accedan por su propia cuenta al mundo que antes les estaba vedado, el mundo de los adultos (Pérez Tornero, 2000, pp. 37-57). De esta manera los medios han venido a recordar que antes de que los aprendizajes adquirieran la forma escuela, los niños se encontraban entremezclados con el

percepción y de lenguaje, a nuevas sensibilidades y escrituras. Radicalizando la experiencia de des -anclaje producida por la modernidad, la tecnología deslocaliza los saberes modificando tanto el estatuto cognitivo como institucional de las condicionas del saber, y conduciendo a un fuerte emborronamiento de las fronteras entre razón e imaginación, saber e información, naturaleza y artificio, arte y ciencia, saber experto y experiencia profana". 
mundo de los adultos, sin los escrúpulos y cuidados con que hoy se los trata y aprendiendo los códigos culturales por medio de prácticas sociales bastante versátiles y efectivas.

De otro lado, la posibilidad de profundizar en la interactividad, otra característica de los nuevos medios, adquiere un sentido pleno en el terreno educativo. El estudiante está en posibilidad de decidir la secuencia de la información que desea seguir, establecer el ritmo, cantidad y profundización de la información que pretende y elegir el tipo de código con el que quiere establecer relaciones con la información. Los anteriores elementos y otros no mencionados, hacen pensar que la educación virtual en las instituciones educativas amerita un acercamiento desde lo conceptual y teórico que fundamente las acciones, procedimientos y rutas que se han de tomar para su realización y para la creación de nuevos ambientes de aprendizaje de calidad y pertinencia social.

\section{BIBLIOGRAFÍA}

Investigaciones

CORTE, Erick de (1995) "Aprender Activamente", en: Ambientes Educativos Dinámicos. Montevideo, Universidad Católica de Uruguay.

FUNDACION FES (1993): Fundación Restrepo Barco, Ministerio de Educación de Colombia. Conocimiento, juego y materiales educativos. Cali.

ROMERO, Hernando (1997): Espacio Educativo, Calidad de la Educación y Acreditación. Bogotá.

RUIZ LÓPEZ, Jairo de Jesús (1995): Aprendizaje desde la gestión educativa, la Integración del pensar, el hacer y el sentir, el Juego y los escenarios educativos frente a los procesos de formación del Liceo Luis Andrade Valderrama De Giraldo Antioquia. Centro Internacional de Educación y Desarrollo Humano. CINDE. Medellín

\section{Libros y revistas}

CANO, María Isabel y ÁNGEL Lledó. (1995): Espacio, comunicación y aprendizaje. Serie Práctica. № 4. Sevilla, Díada Editorial S.L..

Centro de Educación en apoyo a la producción y al medio ambiente. A.C CEP México, Parras. Los ambientes educativos. ¿Generadores de capital humano?. En : Revista Debate en Educación de Adultos. No 7. Medellín, 1997, pp. 15-18.

CHAPARRO, Clara Inés. (1995): El ambiente educativo: condiciones para una práctica educativa innovadora. Especialización en Gerencia de Proyectos Educativos y Sociales. CINDE-UPTC. Tunja,.

DEBRAY, Régis. (1997): Transmitir. Ediciones Manantial, Argentina.

DURAND, Gilbert. La imaginación simbólica. Buenos Aires, Amorrortu Editores, S.F.

GIROUX, Henry. (1990):Los profesores como intelectuales. Hacia una pedagogía crítica del aprendizaje. Barcelona, Ediciones Piados, 
GIROUX, Henry (1.997): Cruzando límites. Trabajadores culturales, y políticas educativas. Barcelona, Paidós,.

Gobernación de Antioquia. Secretaría de Educación y Cultura de Antioquia (2000): La escuela como cátedra viva de convivencia y paz. Orientaciones curriculares y sugerencias didácticas. Medellín.

HUIZINGA, Johanes. (1987): Homo Ludens. México, Fondo de Cultura Económica.

LEROI-GOURHAM, André. (1971): El gesto y la palabra. Caracas, Universidad Central de Venezuela.

MARTÍN-BARBERO, Jesús, “(1996): Heredando el futuro. Pensar la educación desde la comunicación”, en NOMADAS. Comunicación y educación: una relación estratégica, Santafé de Bogotá, número 5 , septiembre

MORENO, Gildardo y MOLINA Adela. (1993): “El ambiente Educativo”, en: Planteamiento en educación. Intervención en planteamiento de planteamientos. Santafé de Bogotá,

NARANJO, José y TORRES, Alfonso (comp.). (1999): Ciudad educativa y pedagogías urbanas. APORTES. № 45. Santafé de Bogotá, Dimensión Educativa, 1996.

OSPINA, Héctor Fabio. Educar, el desafío de hoy: construyendo posibilidades y alternativas. Santafé de Bogotá, Cooperativa Editorial Magisterio.

PEREZ TORNERO, (2000): José Manuel, "Las escuelas y la enseñanza en la sociedad de la información", en: PEREZ TORNERO, José Manuel (comp.), Comunicación y educación en la sociedad de la información, Barcelona, Paidós.

PÉRGOLIS, Juan Carlos (2000): Relatos de Ciudades Posibles. Ciudad educadora y escuela: la práctica significante. Bogotá, Fundaurbana, pp. 33-34.

RESTREPO, Luis Carlos (1993):Intervención en planteamiento de planteamientos, realizado en el planetario Distrital, Bogotá, Marzo de 1993.

RAICHVARG, Daniel (1994): "La educación relativa al ambiente: Algunas dificultades para la puesta en marcha”, en: Memorias Seminario Internacional. La Dimensión Ambiental y la Escuela. Santafé de Bogotá, Serie Documentos Especiales MEN, pp. 2-28.

SAUVE, Lucié. (1994): "Exploración de la diversidad de conceptos y de prácticas en la educación relativa al ambiente", en: Memorias Seminario Internacional. La Dimensión Ambiental y la Escuela. Serie Documentos Especiales. Bogotá, Ministerio. 


\title{
Contactar
}

Revista lberoamericana de Educación

\author{
Principal OEI
}

